\title{
Functional quality, sensorial and shelf life characteristics of Agathi (Sesbania grandiflora (L). Poir leaves enriched breads
}

\author{
Aruna Mesa, Sumana Araveti
}

Professor, Dept. of Home Science (Food Science and Nutrition), Sri Padmavati Mahila Visvavidyalayam, Tirupati, Andhra Pradesh, India

Corresponding author: Sumana Araveti, Research Scholar, Sri Padmavati Mahila Visvavidyalayam, Tirupati, Andhra Pradesh, India

Submission Date: February2 $7^{\text {th }}$, 2017, Acceptance Date: June $28^{\text {th }}, 2017$, Publication Date: June $30^{\text {th }}, 2017$

Citation: Aruna M., Sumana A., Functional quality, sensorial and shelf life characteristics of Agathi (Sesbania grandiflora (L).Poir leaves enriched breads. Functional Foods in Health and Disease 2017; 7(6); 429-441. https://doi.org/10.31989/ffhd.v7i6.339

\begin{abstract}
Background: In our modern life, the burdens of non-communicable diseases such as obesity, cancer, cardiovascular disease, and type- 2 diabetes have increased. By contrast, life expectancy and also cost of health care has increased. Therefore, individuals search other ways to improve or maintain their well-being. In this regard, food and pharmaceutical industries offer functional foods (FFs) with health promoting and disease-preventing properties. Sesbania grandiflora L.Poir is a small, loosely branching tree also known as the local name, Agathi. Agathi belongs to the Fabaceae family, and is one of the most popular green vegetables and traditional medicinal plants of India. The chemical analysis of Sesbania grandiflora leaves reveal it to be a rich source of nutrients and beneficial bioactive compounds, such as antioxidants and polyphenols. Bread has been regarded as one of the most popular food for centuries, as a good source of calories and other nutrients. Bread is traditionally made from wheat flour. The addition of Agathi leaves led to the enhancement of functionality of common bread.
\end{abstract}

Objective: Against the background of this information, the present investigation was undertaken with a clear objective of evaluating the effects of the addition of Agathi leaves on the sensory, textural, and baking characteristics, by examining their microbial quality on a 5day storage period, at an ambient temperature, in different packaging materials, and assessing the improvement, if any, in their antioxidant content.

Methods: Shade dried Agathi leaf powder was analysed for proximate, mineral, and phytochemical composition. Bread samples were prepared with ingredients such as yeast, salt, sugar, water, shortening, baking time, temperature using straight dough process, and varying levels of shade dried Agathi leaves. Physical parameters such as loaf weight, loaf volume, and color values were recorded. Breads were subjected to a sensory evaluation, and in vitro antioxidant capacity was evaluated. 
Results: Addition of leaves to the plain bread is a means of fortification of bread. The leaves of the Agathi plant are rich in nutrients, antioxidants and, dietary fiber. Incorporation of dried leaves to wheat flour shows that the supplemented breads have, in general, enhanced moisture retention capacity, slower staling rate, richer antioxidant content, better baking characteristics, and improved sensory properties in terms of color, texture, mouth feel, and flavor. Shade dried leaves at $10 \%$ level of addition on wheat flour were found to be the optimum level that offered the highest acceptability of the fortified bread.

Conclusion: Results show that the addition of the Agathi leaf powder bettered the crumb moisture content with only a little increase in crumb firmness. A substantial improvement in sensory characteristics was observed with the Agathi supplemented breads. A sharp increase in antioxidant content was an important beneficial fortification effect observed in the fortified breads. Agathi leaf content of 10 gm was found to be the optimum level that offered the best compromise for the highest acceptability of the fortified breads.

Keywords: Functional food, bioactive compounds, In vitro Anti-oxidant capacity.

\section{INTRODUCTION}

The relationship between food and health has an increasing impact on food innovation due to popularity of the concept of functional food. The practice of using nutritional knowledge in food products to improve the health of consumers forms the general concept of functional foods [1]. Nowadays, consumers' demand for low calorie and low fat products has significantly risen in an attempt to limit health problems, to lose or stabilize their weight, and to work within the frame of a healthier diet [2]. The food industry has been confronted with a new challenge to satisfy consumers. In particular, the development of functional products with acceptable sensory characteristics and a competitive price is crucial. In this regard, to meet consumer demands that have been introduced to the market, an increasing number of foods enriched or fortified with plant products may be an alternative route. Moreover, the use of functional ingredients arising from natural sources is preferable compared with the use of synthetic additives, which is less appreciated by consumers.

Foods of plant origin are good sources of functional substances. In fact, the major chemical components found in them include polyphenolics, flavonoid compounds, glucosides, flavonols and flavones, minerals, dietary fibre and phyto estrogens. They are also rich in vitamin $\mathrm{C}$, which increases the body's resistance to external agents, fights free radicals to prevent cell degeneration and the ageing process, protects the eyes and lungs, and has a key role in the process of cell renewal [3].

Bread is the most popular food consumed and appreciated throughout the world; an important staple food made of wheat flour, salt and yeast [4]. It can be considered as a carrier of nutraceutical substances that have a beneficial role in consumer health. In developing functional bakery products (such as bread), it is important to develop a product with physiological effectiveness and consumer's acceptance in terms of appearance, taste and texture [5]. For this reason, industry and researchers are involved in optimizing bread making technology to improve the variety, quality, taste, and availability of food products such as bread [6]. Among the ingredients that could be included in bread formulation, there are herbs and green leafy vegetables, which are an important part of the human diet. They have been used 
for thousands of years to enhance the flavour, colour and aroma of food; and also, for their preservative, anti-oxidative, antimicrobial and other medicinal values.

Sesbania grandiflora is a small, loosely branching tree that grows up to 8-15 $\mathrm{m}$ tall and 25-30 cm in diameter. Sesbania grandiflora L.poir (also known as Agathi) belongs to the Fabaceae family. It is one of the most popular green vegetables and traditional medicinal plants of India. The major contributors of the phenolic substances in Sesbania.grandiflora are simple phenolic acids. Apart from this, the other bioactive compounds reported in this plant are saponins [7]. The juice of leaves of the Sesbania grandiflora have been reported to have anxiolytic, anticonvulsant, antihelmintic, expectorant, and antipyretic effects in the treatment of bronchitis, cough, vomiting, wounds ulcers, diarrhoea, dysentery, etc. Agathi leaves are also known to have antibacterial, antifungal, antidiabetic, antioxidant and antitumorigenic properties [8] .

The present investigation was undertaken with a clear objective for evaluating the effects of the addition of Agathi leaves on the sensory, textural, and baking characteristics of bread. In addition, the investigation examined their microbial quality on a 5-day storage period at ambient temperature in different packaging materials, and assessing the improvement, if any, in their antioxidant content.

\section{Experimental Materials}

For the present study, fresh leaf samples of Sesbania grandiflora(L.)poir were collected from the college garden. The leaves were collected from the same trees to avoid the effect of soil variation on the micronutrient content of the leaves. The collection and taxonomic identification of the specimens were carried out by an expert botanist of the Herbarium of the Botany Department of Sri Krishna Devarya University. Anantapur and the voucher specimen of the collected sample were deposited in the department herbarium for further reference. The specimen was assigned Herbarium No. SKU (No.45767) and taxonomically identified as Sesbania grandiflora(L.)poir as per plant list 2010. Leaves plucked from trees in the college gardens were washed with water to remove any dirt particles and subjected to shade drying. Compressed baker's yeast was used for fermentation of bread. Commercial available wheat flour, sugar, shortenings, and salt were purchased from the local grocery stores at Anantapur, Andhra Pradesh, India.

\section{Chemical analysis of Shade Dried Agathi Leaf (SDAL)powder}

The moisture, protein, total ash, crude fiber contents [9], and total lipids [10] were analysed in leaf samples. The total carbohydrate content was also estimated by a different method. Ash solution was then analyzed for mineral estimation such as calcium [11], phosphorus, iron [12] and total carotenoids [13] . Agathi leaf powder was extracted with $80 \%$ acetone and centrifuged at $10,000 \mathrm{~g}$ for $15 \mathrm{~min}$. The supernatant obtained was analyzed for total phenolics. The total phenolics were estimated using the Folin-Ciocalteau, the method using gallic acid as standard [14] and the results were expressed as gallic acid equivalent (GAE). All analyses were carried out in triplicate samples and expressed as the mean value. The standard deviation was additionally calculated.

\section{Product development}

\section{Bread}

Bread samples were prepared with varying levels of ingredients such as yeast, salt, sugar, water, and shortening. The baking time and temperature followed the straight dough process 
[15]. Accordingly, the baking formula includes wheat flour, compressed active yeast, sugar, salt, shortening and water. The Shade Dried Agathi Leaves (SDAL) quantity used in the different samples per $100 \mathrm{~g}$ of refined wheat flour: $10 \mathrm{~g}, 15 \mathrm{~g}$, and $20 \mathrm{~g}$. The ingredients were mixed in a dough mixer and the rounded dough was fermented in a plastic bowl for one hour. After recovery (20min), the doughs were moulded and placed in the baking pan and proofed for 15 minutes at $30 \pm 5^{\circ} \mathrm{C}$. After proofing, the breads were baked for 25 minutes at $232^{\circ} \mathrm{C}$ in an electric oven. The technological scheme of preparing breads is shown in Figure 1.

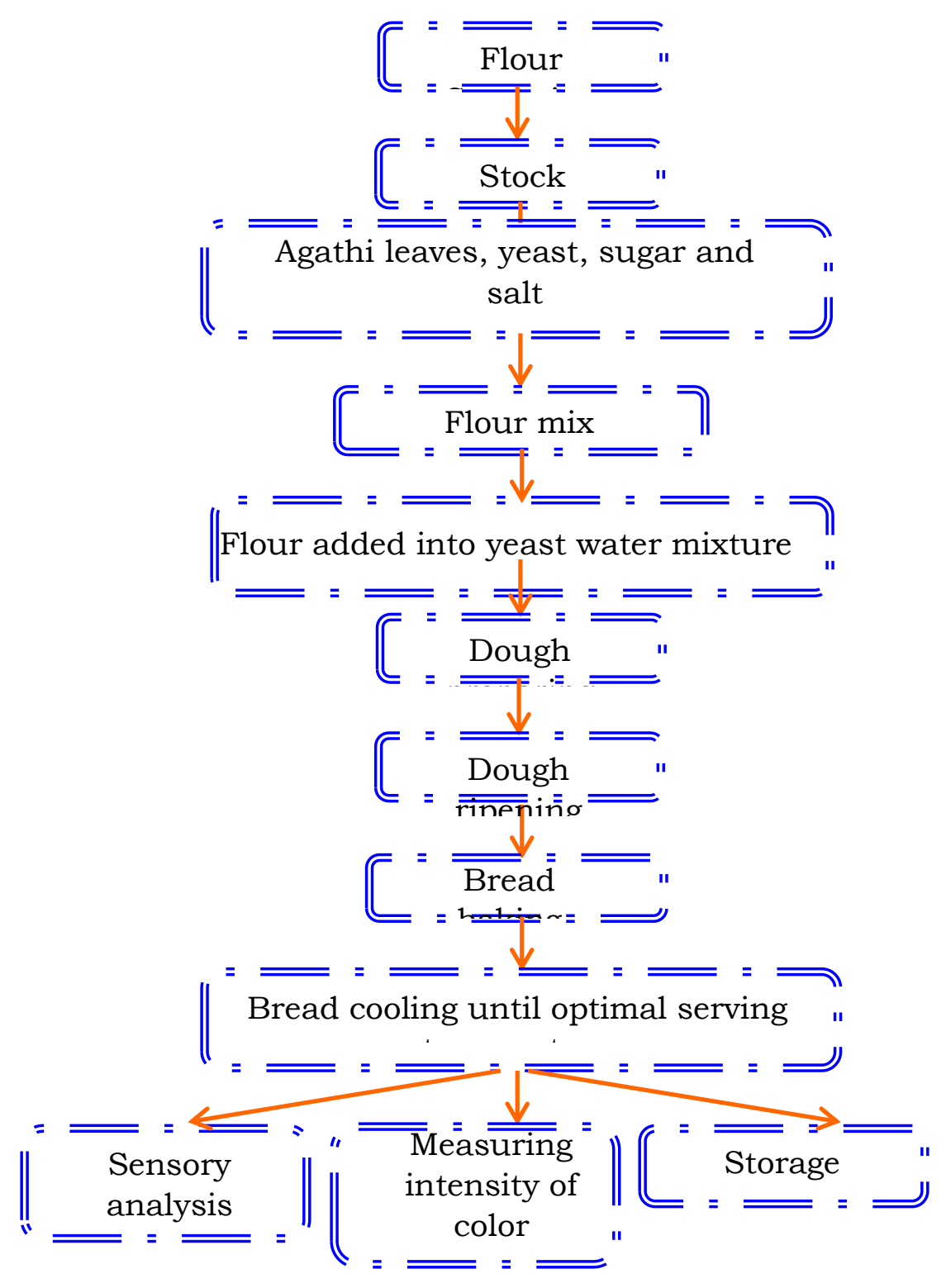

Figure 1. The technological scheme of preparing breads.

\section{Physical Characteristics:}

\section{Loaf volume and loaf weight}

Breads from control and supplemented flours were baked in triplicate samples. After removing from the oven, loaves were immediately weighed and then placed on a wire grid for about 2 hours of cooling before the volumes were determined. Loaf volumes were measured by the rapeseed displacement method as modified by Giami SY [16]. Loaf weight was recorded using laboratory digital balance in control, B1, B2 and B3 breads [17]. 


\section{Color values of bread}

The surface color characteristics of bread samples were measured by a color reader (Konica MINOLTA, CR-10) in terms of ' $L$ ', ' $a$ ' and ' $b$ ' values. The ' $L$ ' values express the whiteness of the sample with 100 as perfect white and ' 0 ' as black. Values of ' $a$ ' and ' $b$ ' indicated redgreen and yellow-blue chromatacity.

\section{Sensory evaluation of breads}

The subjective evaluation of bread samples was carried out for the external sensory characteristics i.e., volume, color of crust, symmetry of form, evenness of bake, character of crust and internal characteristics i.e., grain, colour of crumb, aroma, taste and texture by a trained panel of judges using subjective scoring sheet. The products were scored by the judges according to the method described by Cauvain [18]. This approach goes beyond the simple recording of product attributes and provides framework for making a more objective comparison of baked-product quantities. All the bread samples were sensorially evaluated after 8 hours by a panel of 8 members using a developed score sheet.

\section{Storage studies}

\section{Breads}

The best combination with respect to desirable quality characteristics found during sensory studies was selected to conduct storage stability studies. After the cooling of breads for three hours, the control and enriched breads were packed separately in polyethylene bags and stored at room temperature $\left(25 \pm 2^{\circ} \mathrm{C}\right)$ for 3 and 5 days. All samples were withdrawn after 1,3 , and 5 days and analyzed for staleness of bread by evaluating the bread for crumb taste, crumb texture, and visible mold growth [19] .

\section{Determination of bread anti-oxidant capacity}

\section{Sample extraction procedure}

The methanolic extraction procedure was done as described by [20]. The breads were sliced (about $1 \mathrm{~cm}$ thickness), separated manually, and dried in an electric convection oven at $40^{\circ} \mathrm{C}$ for 24 hours. The dried portion of the bread slices were ground and sieved through a 80-mesh screen to obtain bread powder. Then these materials were extracted in duplicate with methanol $(1: 50 \mathrm{w} / \mathrm{v})$ during 2 hours of swirling at room temperature $\left(25 \pm 1^{\circ} \mathrm{C}\right)$. Samples were then centrifuged at $12000 \mathrm{~g}$ for 15 minutes. The fresh methanolic extracts were used to determine their ability to scavenge DPPH radicals and to assess the total phenolic content.

\section{Determination of total phenolics content}

Total phenolic content was determined using the Folin- Ciocalteau procedure [21]. The reaction mixture contained $100 \mu \mathrm{L}$ aliquot of the sample extract, $500 \mu 1$ of Folin- Ciocalteau reagent, and $1.5 \mathrm{~mL}$ of sodium carbonate. The final volume was made up with $10 \mathrm{~mL}$ of deionised water. After two hours, the reaction of the absorbance at $765 \mathrm{~nm}$ was determined with analytical grade gallic acid (GA), which was used to estimate the phenolic content by using standard curve prepared using gallic acid.

\section{DPPH radical scavenging activity- 1,1-diphenyl-2-picrylhydrazyl (DPPH) radical scavenging activity}

DPPH radical scavenging activity was determined according to the method described by $\mathrm{Yu}$ [22]. This method is based on the ability of cations to scavenge DPPH radical. Breifly $100 \mu \mathrm{L}$ aliquot of the sample extract or standard was added to $2.9 \mathrm{~mL}$ of DPPH reagent $0.1 \mathrm{Mm}$ in 
methanol and vortexed vigorously. It was incubated in the dark for 30 minutes at room temperature, and the discolouration of DPPH was measured against blank at $517 \mathrm{~nm}$.

\section{Calculation:}

DPPH Scavenged $(\%)=(1-$ sample O.D./ blank O.D. $) \times 100$

\section{Statistical Analysis}

All analyses were performed in triplicate samples and the data was reported as mean \pm SD. Results were subjected to analysis of variance technique (ANOVA) to determine the difference of means, and $\mathrm{P} \leq 0.05$ was considered to be statistically significant [23].

\section{RESULTS AND DISCUSSIONS}

\section{Chemical analysis of Shade Dried Agathi Leaves (SDAL) powder}

The proximate composition of SDAL is shown in Table 1 . The chemical analysis revealed Agathi leaves to be richer in nutrients and polyphenols. The leaves were found to be rich in protein, calcium, fibre and polyphenols. They were moderately rich in other nutrients, which indicates Agathi leaves to be a potential source of good nutrient availability. The proximate composition reported was comparable to the earlier report. Among the bioactive compounds, Agathi leaves were analysed for total polyphenols. The total polyphenol content of Agathi leaves was estimated to be $44.40 \mathrm{mg} / 100 \mathrm{~g}$ gallic acid equivalent (GAE) .

Table 1. Nutrient and bioactive composition of shade dried agathi leaves (SDAL).

\begin{tabular}{|l|l|}
\hline Component & Content \\
\hline Moisture & $72.76 \pm 1.0$ \\
\hline Fat & $3.40 \pm 0.2$ \\
\hline Ash & $3.51 \pm 0.2$ \\
\hline Protein & $8.70 \pm 0.5$ \\
\hline Total carbohydrate & $14.6 \pm 0.24$ \\
\hline Fibre & $2.38 \pm 0.05$ \\
\hline Calcium (mg) & $1130 \pm 42.7$ \\
\hline Iron (mg) & $6.70 \pm 0.25$ \\
\hline Phosphorous(mg) & $75.25 \pm 1.25$ \\
\hline Total Carotenoids (mg) & $42.3 \pm 1.15$ \\
\hline$\beta-$ carotene (mg) & $15.2 \pm 0.23$ \\
\hline $\begin{array}{l}\text { Total polyphenols } \\
\text { (mgGAE/100g) }\end{array}$ & $44.40 \pm 1.25$ \\
\hline
\end{tabular}

* Values reported on dry weight basis

Values are Mean \pm SD of three values

\section{Physical characteristics}

The physical characteristics of bread formulation are presented in Table 2. Desirable loaf height and volume were observed in control formulation. Addition of Agathi leaves at 10 percent (B1), 15 percent (B2), and 20 percent (B3) levels resulted in a decrease in the loaf heights and volume significantly $(\mathrm{p} \leq 0.01)$. The loaf weight of the bread samples showed a 
significant increase as the addition of Agathi leaves increased (Table 2). This trend could be due to an increased amount of water absorbed by the dry herbal powder during dough making and its retention to a large extent in subsequent baking processes. The volume of the bread loaves was observed to decrease with increase in the substitution level of Agathi leaves. An increase in Agathi leaves substitution, deteriorates the gluten network in the dough, which actually lowers the $\mathrm{CO} 2$ gas retention capacity of the dough causing a decrease in the loaf volume. Crushed leaves lightly interfere with the bubbles during mixing and their entrapment with the dough deters further expansion. The results of loaf height and loaf volume are higher than recorded values [24]. Loaf weight of the supplemented bread (B1, B2 and B3) differ significantly $(p \leq 0.01)$ from the control. The increase in the weight of the breads could probably be due to the increasing level of the addition of shade dried Agathi leaves. Herbal bread formulation containing different percentages of aloe vera gel revealed an increase in the loaf weight with a subsequent increase in the percentage of gel [25].

Table 2. Physical characteristics of developed bread formulations

\begin{tabular}{lccc}
\hline Bread Sample & ** Loaf height $(\mathbf{c m})$ & ** Loaf weight $(\mathbf{g})$ & ** Loaf volume $\left(\mathbf{c m}^{\mathbf{3}}\right)$ \\
\hline C & $6.97 \pm 0.05$ & $399 \pm 0.82$ & $663.67 \pm 1.25$ \\
B1 & $6.83 \pm 0.05$ & $447.67 \pm 2.05$ & $659.67 \pm 0.47$ \\
B2 & $5.47 \pm 0.05$ & $459.33 \pm 0.94$ & $619.67 \pm 1.25$ \\
B3 & $5.03 \pm 0.05$ & $464 \pm 1.41$ & $590 \pm 8.16$ \\
F $_{\text {calculated }}$ & 847.58 & 913.56 & 140.12 \\
CD $(\mathrm{p}<0.05)$ & 5.58 & 171.38 & 201.35 \\
CD $(\mathrm{p}<0.051$ & 10.42 & 319.94 & 375.89 \\
\hline
\end{tabular}

$\mathrm{F}_{\text {tabulated }}=4.066(\mathrm{p} \leq 0.05)^{*} ; 7.59(\mathrm{p} \leq 0.01)$

$* *$ Values are mean \pm S.D. of 3 replicate

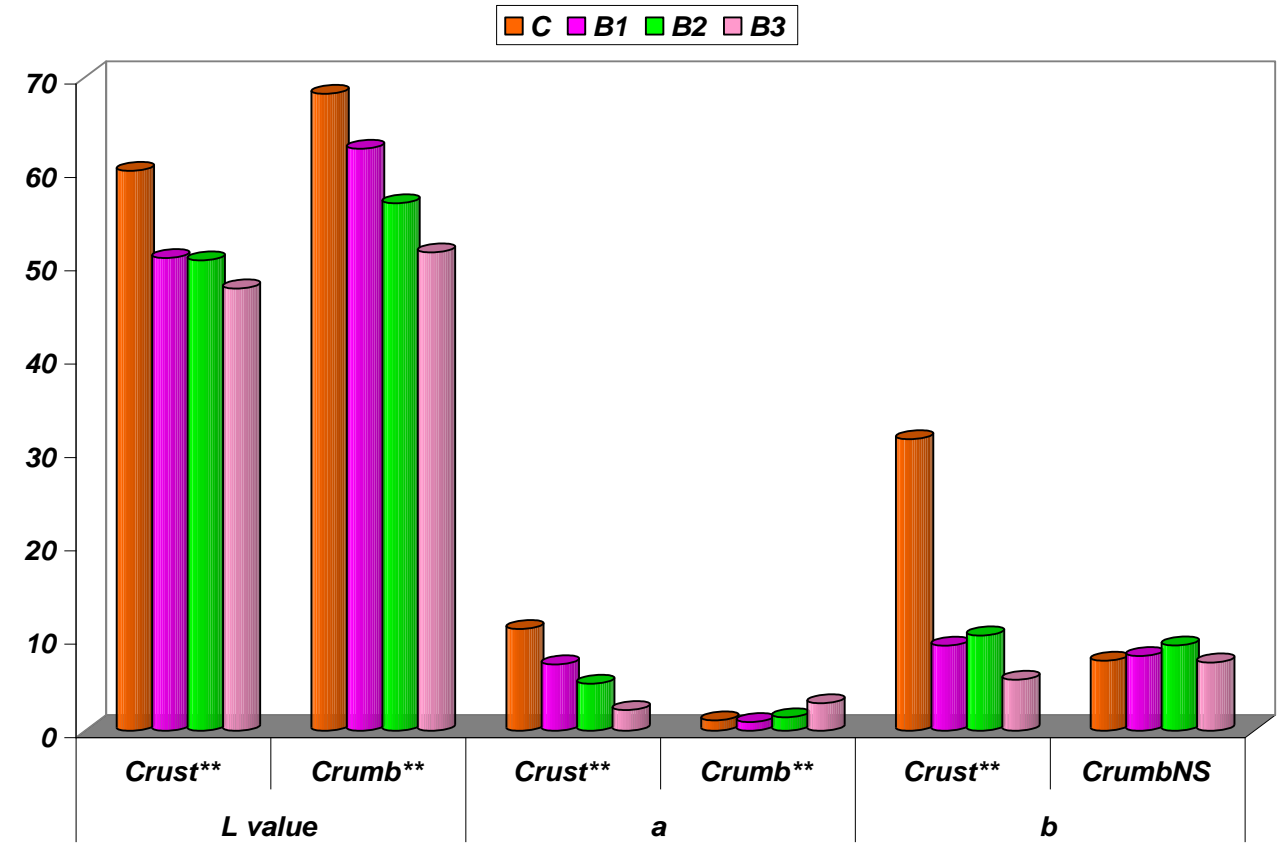

Figure 2. Color values of agathi leaf incorporated breads

$$
\begin{aligned}
& \mathrm{F}_{\text {tabulated }}=4.066(\mathrm{p} \leq 0.05) * ; 7.591(\mathrm{p} \leq 0.01) * * \\
& \text { NS - Non-significant } \\
& * \text { Values are mean } \pm \mathrm{SD} \text { of } 3 \text { replicates }
\end{aligned}
$$


Color of bread products is evaluated at two places, the crust and the crumb. The crust color and crumb color values of control, and formulated breads B1, B2 and B3 are presented in Figure 2. Visual differences in brightness were $(\mathrm{p} \leq 0.01)$ significantly observed in control and developed breads. The crumb and the crust color of the control and the treated bread samples were measured after cooling to room temperature. The crust color of the bread samples showed monotonic variation in all the 3 aspects of $\mathrm{L}^{*}, \mathrm{a}^{*}$, and $\mathrm{b}^{*}$. With the increase in the Agathi leaf supplementation, the brightness ( $\mathrm{L}^{*}$-value), redness ( $\mathrm{a}^{*}$-value), and the yellowness (b*-value) of the crust decreased. The dark coloration of the crusts was the effect of the Maillard browning reaction between reducing sugars and amino acids, which is influenced by the distribution of water and the color of the herb.

As seen in Figure 2 , the crumb color lightness ( $\left.\mathrm{L}^{*}\right)$, redness $\left(\mathrm{a}^{*}\right)$, and yellowness $\left(\mathrm{b}^{*}\right)$ are all affected significantly (at $\mathrm{p} \leq 0.05$ ) on supplementation. With the increase in the level of supplementation, the $\mathrm{L}^{*}$-value decreased, but the $\mathrm{a}^{*}$-value increased in contrast to the trend observed with the crust. The crumb, as such, generally does not undergo any substantial extent of Maillard reaction. The darker crumb color in the fortified breads may thus be attributed to the added Agathi leaf powder, which has a darker shade than the wheat flour. The fortified bread crumbs were found to be more yellowish in shade compared to the controlled. However, the depth of yellow, brightness (L) value decreased with an increased level of addition of shade dried leaves and the changes in redness (a) values decreased marginally in crust and crumb characteristics of the developed breads significantly at the 1 percent level. A significant observation regarding the low ' $a$ ' value is a marked indication of addition of shade dried Agathi leaves. Agathi leaves containing $\beta$-carotene undergo changes upon baking, thus influencing the color characteristics of breads. These color changes are mainly because Agathi leaves are rich in polyphenols, which are substrates for the enzymes involved in browning. Therefore, due to the enzymatic browning, brightness and yellowness of the breads may be decreased. Also, shade dried Agathi leaves have acquired a yellowish tinge color, with their incorporation with refined flour also decreasing the brightness of the breads.

Sensory attributes for the bread products have been classified as external characteristics (volume, colour of crust, form symmetry, evenness of bake, crust character) and internal characteristics (grain, colour of crumb, aroma, taste and texture). The statistical results for volume of bread prepared with different levels of leaves differed from control and with each other. The scores assigned by the panelists for form symmetry of breads prepared from different levels of shade dried leaves indicated (Table 3) a proportionate significant increase. The statistical results regarding scores assigned to taste and texture of the bread samples were not statistically significant.

Crust character decreased with increased levels of incorporation with a range of scores 3 to 2.6. The Crust color and crumb color of baked products are usually golden brown. This may be as a result of caramelization of sugars and also due to browning reaction of protein and reducing sugar. 
Table 3. Sensory quality of bread containing different levels of shade dried Agathi leaves

\begin{tabular}{|c|c|c|c|c|c|c|c|c|}
\hline Sensory & Max. & \multicolumn{4}{|c|}{$\underline{\text { Level of incorporation }}$} & \multirow[t]{2}{*}{$\mathbf{F}_{\text {calculated }}$} & \multirow[t]{2}{*}{$\mathrm{CD}(\mathrm{p}<0.05)$} & \multirow[t]{2}{*}{$\mathrm{CD}(\mathrm{p}<0.01)$} \\
\hline $\begin{array}{l}\text { External } \\
\text { Characteristics }\end{array}$ & & $\mathbf{C}$ & B1 & B2 & B3 & & & \\
\hline Volume & 10 & $\begin{array}{l}8.13 \pm \\
0.33\end{array}$ & $\begin{array}{l}6.75 \pm \\
1.20\end{array}$ & $\begin{array}{l}7 \pm \\
1.32\end{array}$ & $\begin{array}{l}6.38 \pm \\
1.22\end{array}$ & 3.32 & 3.14 & -- \\
\hline Color of crust & 8 & $\begin{array}{l}6.75 \pm \\
0.83\end{array}$ & $\begin{array}{l}5.75 \pm \\
0.97\end{array}$ & $\begin{array}{l}6.13 \pm \\
1.17\end{array}$ & $\begin{array}{l}6.25 \pm \\
1.56\end{array}$ & 0.88 & -- & -- \\
\hline Form Symmetry & 5 & $\begin{array}{l}2.38 \pm \\
0.48\end{array}$ & $\begin{array}{l}2.63 \pm \\
0.86\end{array}$ & $\begin{array}{l}3.75 \pm \\
0.83\end{array}$ & $\begin{array}{l}3.75 \pm \\
0.43\end{array}$ & 8.07 & 3.04 & 4.71 \\
\hline $\begin{array}{l}\text { Evenness } \\
\text { of bake }\end{array}$ & 3 & $\begin{array}{l}2.25 \pm \\
0.66\end{array}$ & $\begin{array}{l}2.13 \pm \\
0.60\end{array}$ & $\begin{array}{l}2.38 \pm \\
0.48\end{array}$ & $\begin{array}{l}2.25 \pm \\
0.66\end{array}$ & 0.2 & -- & -- \\
\hline Crust character & 4 & $\begin{array}{l}3 \pm \\
0.71\end{array}$ & $\begin{array}{l}2.75 \pm \\
0.43\end{array}$ & $\begin{array}{l}2.75 \pm \\
0.66\end{array}$ & $\begin{array}{l}2.63 \pm \\
0.86\end{array}$ & 0.37 & -- & -- \\
\hline $\begin{array}{l}\text { Internal } \\
\text { Characteristics }\end{array}$ & & & & & & & & \\
\hline Grain & 15 & $\begin{array}{l}11.86 \\
\pm 1.54\end{array}$ & $\begin{array}{l}11.25 \\
\pm 2.38\end{array}$ & $\begin{array}{l}12 \pm \\
1.66\end{array}$ & $\begin{array}{l}12.63 \pm \\
1.73\end{array}$ & 0.65 & -- & -- \\
\hline $\begin{array}{l}\text { Color } \\
\text { of Crumb }\end{array}$ & 10 & $\begin{array}{l}8.38 \pm \\
1.11\end{array}$ & $\begin{array}{l}8 \pm \\
0.87\end{array}$ & $\begin{array}{l}6.75 \pm \\
1.64\end{array}$ & $\begin{array}{l}7.38 \pm \\
1.65\end{array}$ & 1.80 & -- & -- \\
\hline Aroma & 10 & $\begin{array}{l}7.75 \pm \\
1.09\end{array}$ & $\begin{array}{l}6.13 \pm \\
1.17\end{array}$ & $\begin{array}{l}6.88 \pm \\
1.27\end{array}$ & $\begin{array}{l}6.75 \pm \\
1.85\end{array}$ & 1.65 & -- & -- \\
\hline Taste & 20 & $\begin{array}{l}17.5 \pm \\
1.85\end{array}$ & $\begin{array}{l}14.38 \\
\pm 3.04\end{array}$ & $\begin{array}{l}14.13 \\
\pm 2.89\end{array}$ & $\begin{array}{l}16.63 \pm \\
2.69\end{array}$ & 2.46 & -- & -- \\
\hline Texture & 15 & $\begin{array}{l}12.86 \\
\pm 1.69\end{array}$ & $\begin{array}{l}11.5 \pm \\
1.0\end{array}$ & $\begin{array}{ll}12 & \pm \\
1.5 & \end{array}$ & $\begin{array}{l}12.5 \pm \\
1.22\end{array}$ & 1.32 & -- & -- \\
\hline
\end{tabular}

$\mathrm{F}_{\text {tabulated }}=2.95(\mathrm{p} \leq 0.05)^{*} ; 4.57(\mathrm{p} \leq 0.01)^{* *}$

Values are mean \pm S.D. of 8 replicates

\section{Storage}

Sensory characteristics (crumb taste and crumb texture) of breads packed in polythene bags showed a significant $(\mathrm{p} \leq 0.01)$ difference over the storage period. Bread crumb becomes hard and crumbly and loses its elasticity with storage. Storage of breads in polythene pouches showed a significant $(\mathrm{p} \leq 0.01)$ gradual decrease in sensory characteristics over the storage period. Packaging material showed comparable effect on sensory characteristics of developed bread identified in Table 4. Visible mold growth was not detected even after 5 days of storage. This may be attributed to the addition of shade dried Agathi leaves having antimicrobial, antibiotic and antioxidative properties. 
Table 4. Effect of storage on the sensory and microbial quality of breads packed in polyethylene bags

\begin{tabular}{|c|c|c|c|c|c|c|c|c|c|}
\hline \multicolumn{10}{|c|}{ Storage Period (days) } \\
\hline \multicolumn{4}{|c|}{ ( } & \multicolumn{4}{|l|}{3} & \multicolumn{2}{|l|}{5} \\
\hline $\mathbf{C}$ & B1 & B2 & B3 & $\mathbf{C}$ & B1 & B2 & B3 & $\mathbf{C}$ & B1 \\
\hline 17.25 & 14.38 & 14.13 & 16.5 & 7.25 & 13.38 & 13.38 & 12.5 & 16.25 & 12.63 \\
\hline \pm 1.75 & \pm 2.87 & \pm 2.73 & \pm 2.54 & \pm 1.62 & \pm 4.19 & \pm 4.19 & \pm 3.27 & \pm 1.62 & \pm 4.32 \\
\hline 12.88 & 11.5 & 12 & 11.25 & 12.75 & 11.5 & 11.5 & 12.25 & 11.75 & 10.38 \\
\hline \pm 1.59 & \pm 0.94 & \pm 1.41 & \pm 1.55 & \pm 1.55 & \pm 1.63 & \pm 1.63 & \pm 1.81 & \pm 1.55 & \pm 1.82 \\
\hline \multirow[t]{2}{*}{ ND } & ND & $\mathrm{ND}$ & ND & ND & ND & ND & ND & ND & ND \\
\hline & & & \multicolumn{2}{|r|}{$F_{\text {tabulated }}$} & \multicolumn{2}{|c|}{$F_{\text {calculated }}$} & \multicolumn{2}{|c|}{$\mathrm{CD}(\mathbf{p}<0.05)$} & $\mathrm{CD}(\mathrm{p}<0.01)$ \\
\hline \multicolumn{3}{|c|}{ Treatment $(\mathrm{T})^{* *}$} & \multicolumn{2}{|r|}{3.897} & \multicolumn{2}{|c|}{109.669} & \multicolumn{2}{|l|}{47.250} & 77.17 \\
\hline \multicolumn{3}{|c|}{ days (D)** } & \multicolumn{2}{|r|}{1.846} & \multicolumn{2}{|c|}{4.008} & 4.274 & \multicolumn{2}{|r|}{5.27} \\
\hline \multicolumn{3}{|c|}{$\begin{array}{l}\text { Treatment } \times \text { days } \\
(T \times D)^{N S}\end{array}$} & \multicolumn{2}{|r|}{1.846} & \multicolumn{2}{|c|}{0.812} & 1.926 & \multicolumn{2}{|c|}{2.57} \\
\hline
\end{tabular}

** Significant at $1 \%$ level

NS - Non significant; ND - Not detected

Values are mean \pm S.D. of 8 replicates

\section{Antioxidant analysis}

The total polyphenolic content of bread samples found in the present study are presented in Table 5. The amount of phenolics increased proportionally to the increase of shade dried Agathi leaves (SDAL) in comparison with the control bread. Phenolic content of enriched breads increased with an increase in the percent addition of SDAL. Heating alters the phenolic antioxidants in many ways. Baked bread had a slightly higher antioxidant activity than fermented dough. Heat treatment changed the antioxidant activity of the bread. Increasing baking temperature and time might release the insoluble conjugated bound phenolic compounds, which resulted in increasing antioxidant properties. Furthermore, Maillard products formed during heating may have contributed to the antioxidant activity of baked bread.

Table 5. Total phenolic content of Agathi leaves incorporated breads with different levels of substitution

\begin{tabular}{|l|c|}
\hline Substitution level $(\mathbf{g} / \mathbf{1 0 0 g})^{\#}$ & $\begin{array}{l}\text { Total phenolics content }(\mathrm{mg} / 100 \mathrm{~g} \text { gallic } \\
\text { acid equivalent }(\mathrm{GAE})\end{array}$ \\
\hline 0 & $28.7 \pm 1.5$ \\
\hline 10 & $40.5 \pm 2.5^{*}$ \\
\hline 15 & $46.4 \pm 2.3^{*}$ \\
\hline 20 & $52.5 \pm 2.6^{*}$ \\
\hline
\end{tabular}

\#Value of TPC are means \pm SD $(n=3)$.

Different levels exhibiting significant differences among the different percentages of Agathi leaves $(\mathrm{p} \leq 0.05)$. 
DPPH is a stable free radical compound and is widely used to test the free radical scavenging ability of various antioxidants As the antioxidants donate proton to this radical, the absorption due to DPPH radical decreases. The extent of inhibition, expressed in percent decrease in absorbance at $517 \mathrm{~nm}$ of the original DPPH solution, shows a sharp and almost linear increase in antioxidant activity with the level of Agathi leaf supplementation; it increased considerably to $37 \%$ with addition of $10 \mathrm{~g}$ of SDAL. A further increase in scavenging activity was seen for $15 \mathrm{~g}$ and $20 \mathrm{~g}$ with a value of $44 \%$ and $62 \%$ respectively (Figure 4 ). An excellent parallel correlation between the TPC assay and the percentage of inhibition of DPPH confirms to the above inference. It can also be inferred that the phenolic compounds are primarily responsible for the antioxidant activities in the Agathi leaf supplemented bread samples.

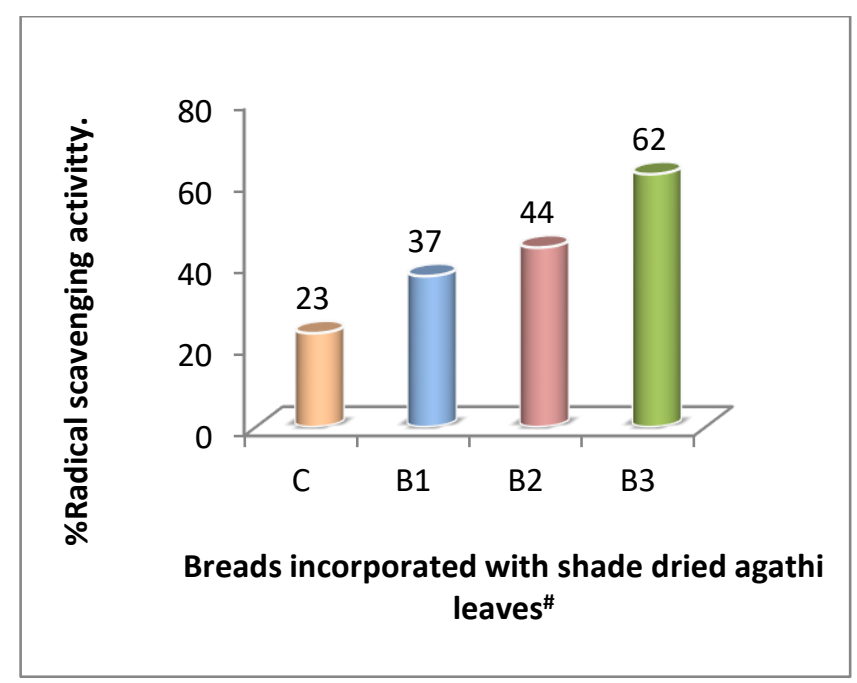

Figure 4. Effect of Agathi leaves incorporation on DPPH radical scavenging activity of breads. *methanolic extracts of sample at the concentrations of $100 \mathrm{mg} / \mathrm{ml}$.

\section{CONCLUSION}

It can be concluded that supplementation of refined flour by plant based products is a new approach towards fortification of white bread. The leaves, stem, roots, and seeds of plant based products are rich in minerals, micronutrients, antioxidants, and dietary fibers. Agathi is one of the most commonly used herbs known over centuries, its leaves are being extensively used as garnish and as a traditional source. Incorporation of dried and powdered Agathi leaves into refined wheat flour shows that the supplemented breads have, in general, enhanced moisture retention capacity, slower staling rate, richer antioxidant content, better baking characteristics, and improved sensory properties in terms of color, texture, mouthfeel, and flavor. Powder leaf content between $10 \mathrm{~g}$ and $15 \mathrm{~g}$ on wheat flour was found to be the optimum supplementation level offering the highest acceptability of the fortified bread. The ability to delay or even prevent lipid oxidation in bread with extended shelf life would entail an improvement in flavor stability and an enhancement in consumer satisfaction. Moreover, a product with a higher oxidative stability could contribute to a reduction in the amount of bread returns. Use of natural antioxidants constitutes possible strategies for postponing lipid oxidation and reducing of flavour deteriorations. Agathi leaves based breads have exhibited extended shelf life replacing the need for synthetic antioxidants.

Results indicated that Agathi leaves can be incorporated in breads as a functional ingredient at $10 \mathrm{gm} / 100 \mathrm{gm}$ of refined wheat flour, without negatively affecting the physical and 
sensory quality. At $10 \mathrm{gm}$ level incorporation, the breads nutritive and phytochemical composition (polyphenols and carotenoids) have more than that of the control biscuits. As a result of the increase in bioactive compounds content, the IC50 value at 10 gm level increased by two fold compared to the control bread powder. Breads containing shade dried Agathi leaves can thus be developed as a health-promoting functional food.

List of Abbreviations: FFs, Functional foods; SDAL, shade dried agathi leaves; DPPH- 1,diphenyl-2-picrylhydrazyl (DPPH) radical scavenging activity; GA- gallic acid GAE-gallic acid equivalent.

Authors' Contribution: Dr. Aruna Mesa contributed to support and prepared the manuscript. Sumana Araveti conducted the study.

Competing Interests: First author related to this study is an employee of Department of Home Science, Sri Padmavati Mahila Visvavidyalayam, Tirupati, AP, India. Second author is a research scholar in the department of Home Science, Sri Padmavati Mahila Visvavidyalayam, Tirupati, AP, India. The authors declare no conflict of interest associated with this manuscript.

Acknowledgments and Funding: The authors gratefully acknowledge the excellent research ambience provided at the Dept. of Home Science, Sri Padmavati Mahila Visvavidyalayam, Tirupati and Dept. of Food and Nutritional Sciences, Sri Sathya Sai Institute of Higher Learning.

\section{REFERENCES}

1. Peressini D, Sensidoni A: Effect of soluble dietary fibre addition on rheological and bread making properties of wheat doughs. Journal of Cereal Science 2009, 49(2): 190201.

2. Sandrou DK, Arvanitoyannis I: Low-fat/calorie foods:current state and perspectives. Critical Reviews in Food Science and Nutrition 2000, 40: 427-447.

3. Schieber A, Stintzing, FC, Carle R: By-products of plant food processing as a source of functional compounds - recent developments. Trends in Food Science \& Technology 2001, 12: 401-413.

4. Fan L, Zhang S, Yu L, Ma L: Evaluation of antioxidant property and quality of breads containing Auricularia auricula polysaccharide flour. Food Chemistry 2006, 101 (suppl 3):1158-1163.

5. Siró I, Kápolna E, Kápolna, B, Lugasi A: Functional food. Productdevelopment, marketing and consumer acceptance- a review. Appetite 2008, 51(suppl 3):456-467.

6. Hathorn CS, Biswas MA, Gichuhi PN, Bovell-Benjamin AC: Comparison of chemical, physical, micro-structural, and microbial properties ofbreads supplemented with sweet potato flour and high-gluten dough enhancers. LWT - Food Science and Technology 2008, 41(suppl 5): 803-815.

7. Wagh, VD, Wagh, KV, Tandale YN, and Salve, SA: Phytochemical, Pharmacological and Phytopharmaceutics Aspects of Sesbania grandiflora (Hadga), A Review. Journal of Pharmacy Research 2009:,2(5): 889-892. 
8. Venkateshwarlu S, Shiddamallayya K: Traditional and ayurvedic medicinal importance of agasthya leaves [Sesbania grandiflora ( L. ) pers .] W . R . T. Its pharmacognostic and physicochemical evaluation 2012: 3(Suppl 2), 193-197.

9. AOAC. Official Methods of Analysis. 16th ed. Washington DC: Association of Official Analytical Chemists; 1995.

10. Huber DJ, Newman DW: Relationship between lipid changes and plastic ultra structural changes in soyabean cotyledons. J Exp Biol 1975, 27.490 - 511.

11. Hawk OBL, Summerson (Eds.): Practical Physiological Chemistry. $13^{\text {th }}$ Edn; 1957: 644.

12. Raghuramulu N, Madhavan NK, Kalyansundaram: A Manual of Laboratory Techniques National Institute of Nutrition, ICMR, Hyderabad 2003: 319-320.

13. Ranganna S: Handbook of Analysis and Quality Control for Fruit and Vegetable Products. Tata McGraw- Hill Publishing Company Limited, New Delhi 1986, 40-42.

14. Kahkonen MP, Hopia AI, Vnorela HI, Rauha JP, Pihlaja K, Kujala TS, Heinonen M: Antioxidant activity of plant extrats containing phenolic compounds. J Agric Food Chem 1999, 47: 3954 - 3962.

15. AACC Approved methods of American Association of Cereal Chemists. $9^{\text {th }}$ ed. St. Paul, $\mathrm{MN} ; 1990$.

16. Giami SY, Amasisis T, Ekiyor, G: comparision of bread making properties of composite flour from kernds of roasted and boiled African Bread Fruit (Treculia African Decne) Seeds. Journal of Raw Material Research 2004, 1: 16 - 25.

17. ISI. IS: 1483. Indian Standard Specification for white bread. Bureau of Indian Standards, New Delhi: 1968.

18. Cauvain SP, Young L: Baked Products. UK: Blackwell Publishing Ltd; 2006: 18 - 21.

19. Aneja, KR: Experiments in Microbiology, Plant Pathology, Tissue Culture and Mushroom Production Technology. $3^{\text {rd }}$ ed. New Delhi: New Age International (P) Ltd; 2001.

20. Sreeramulu D, Reddy CVK, Raghunath, M: Antioxidant activity of commonly consumed cereals, millets, pulses and legumes in India. Indian Journal of Biochemistry and Biophysics 2009, 46.112-115.

21. Kahkonen MP, Hopia AI, Vnorela HI, Rauha JP, Pihlaja K, Kujala TS, Heinonen M: Antioxidant activity of plant extrats containing phenolic compounds. J Agric Food Chem 1999, 47: 3954 - 3962.

22. Yu L, Haley S, Perret J, Harris J, Qian M: Free radical scavenging properties of wheat extracts. Journal of agricultural and Food chemistry 2002,86: 1619-1624.

23. Gupta SK: Statistical Methods. New Delhi: Sultan Chand and Sons Publications; 2007: 234-250.

24. Singh A, Singh KA: Optimization of processing variables for the preparation of herb bread using Aloe vera gel. Food Si Technol 2009, 46 (suppl 4): 335-338. 